Article

\title{
Exploring the Roles of Self-Efficacy and Technical Support in the Relationship between Techno-Stress and Counter-Productivity
}

\author{
Dae Geun Kim ${ }^{1}$ and Chang Won Lee ${ }^{2, *(D)}$ \\ 1 Faculty of New Industry Creation, Daekyeung University, Gyeongsan 38547, Korea; essekim@tk.ac.kr \\ 2 School of Business, Hanyang University, Seoul 04763, Korea \\ * Correspondence: leecw@hanyang.ac.kr; Tel.: +82-2-2220-2790
}

Citation: Kim, D.G.; Lee, C.W. Exploring the Roles of Self-Efficacy and Technical Support in the Relationship between Techno-Stress and Counter-Productivity. Sustainability 2021, 13, 4349. https:// doi.org/10.3390/su13084349

Academic Editor: Hyo Sun Jung

Received: 2 March 2021

Accepted: 12 April 2021

Published: 14 April 2021

Publisher's Note: MDPI stays neutral with regard to jurisdictional claims in published maps and institutional affiliations.

Copyright: (c) 2021 by the authors. Licensee MDPI, Basel, Switzerland. This article is an open access article distributed under the terms and conditions of the Creative Commons Attribution (CC BY) license (https:// creativecommons.org/licenses/by/ $4.0 /)$.

\begin{abstract}
Organizational reliance on information and communication technology (ICT) is more likely to induce techno-stress as a detrimental effect, which has a negative impact on productivity. Businesses should make organizational efforts to decrease counter-productivity, a negative effect of techno-stress, to create sustainable productivity by taking advantage of information and communication technology. The purpose of this study was to explore the roles of self-efficacy and technical support as moderating variables in the relationship between techno-stress and counter-productivity. This study selected techno-overload, techno-invasion, techno-complexity, techno-insecurity, and techno-uncertainty as the techno-stress measurement variables, as well as counterproductive work behavior (CWB) and innovation resistance as counter-productive measurement variables. In this study, we surveyed 700 people in the IT sector, manufacturing, services, public agencies, and other industries and used regression analysis to analyze the effects of self-efficacy and technical support. As a result of the analysis, techno-overload, techno-invasion, techno-insecurity, and techno-uncertainty have positive effects on CWB and innovation resistance whereas self-efficacy and technical support have moderating effects on techno-stress and counter-productivity by interacting with techno-overload, techno-insecurity, and techno-uncertainty. We suggest measures to strengthen self-efficacy and technical support for mitigating counterproductive work behavior and innovation resistance.
\end{abstract}

Keywords: techno-stress; counter-productivity; self-efficacy; technical support; counterproductive work behavior; innovation resistance

\section{Introduction}

The rapid development of information and communication technology (ICT) since the second half of the 20th century has caused the environments inside and outside companies to change dramatically. Companies have been taking advantage of new ICTs as strategic means to improve the elements which have relationships with productivity, such as achieving organizational goals, innovation, communication, and prediction over environmental change. Information in business settings is valuable data to decision-makers. For example, putting innovative technologies like the differentiation of information systems in businesses improves efficiency and productivity. This is an innovation process involving a competitive advantage from dealing with the dynamic environment in terms of a resource-based perspective. There is a criticized argument that information technology does not have a positive relationship with improvements of efficiency and productivity [1], i.e., businesses might take the disadvantage of improving performance from applying new information technology.

From the person-environment fit theory of Edward et al. [2], the misfit between individuals and the environment in organizations caused by employing new or innovative information technology into the production process can produce detrimental effects like stress or psychological pressure on employees. As a result, counterproductive behavior may 
have no outcome despite the efforts to strengthen the suitability between the individual and the environment. The detrimental effects from the adoption and use of new technologies or information technologies in the production process involve the concept of techno-stress. Techno-stress refers to the detrimental effects that employees suffer from differences of the access to and use of technology, a type of stress from the maladaptation of new information technology [3]. Techno-stress is a negative effect on efficiency and productivity in the adoption of new technology or information technology. Tu et al. [4] stated that technostress caused work overload, lower morale, discouragement, information fatigue, loss of motivation, and dissatisfaction at work. Soylu and Campbell [5] presented that technostress has a negative relationship with job satisfaction and productivity in organizations with failure in adopting new information technology. Tarafdar et al. [6] defined the negative effect caused by the introduction of new technology or information technology as the information technology paradox, urging studies on the causes and solutions of technostress. There have been academic outcomes to explore techno-stress empirically and theoretically. They have depended on an individual approach for the causes of technostress and ways to relieve it. There is, however, a lack of research regarding an integrated approach to examine the impact of techno-stress on business and its employees, including actions to curb dysfunctions and pathology from techno-stress. The purpose of this study was to empirically test the effect of techno-stress, a detrimental effect of the introduction of information technology, on counter-productivity and further examine the moderating effect of self-efficacy and technical support in the causal relationship between techno-stress and counter-productivity.

The paper has five sections. Section 1 introduces the purpose of the study. Section 2 presents the theoretical background to focus on techno-stress, counter-productivity, current studies in the relationship between techno-stress and counter-productivity, and mitigation of techno-stress and counter-productivity. Section 3 presents the research design with a research mode. Section 4 provides the results of analysis including validity test, reliability test, correlation analysis, and hierarchical regression analysis on exploring the role of self-efficacy and technical support in the relationship between techno-stress and counterproductivity. Section 5 discusses overall implications from the study analysis along with the study's limitations, and Section 6 presents concluding remarks of the study findings along with its further research directions.

\section{Theoretical Background}

\subsection{Definition of Techno-Stress}

Techno-stress is a word that combines technology and stress. Brod [7] first defined the condition caused by the lack of efforts for individuals and organizations to adapt to the introduction of new technology or information technology as techno-stress. Arnetz and Wiholm [8] described techno-stress as a state of mental and physiological arousal observed in people who are heavily dependent on technology to perform their work, which occurs when people find their work stimulating, but feel they do not have the necessary skills to cope with technology. Weil and Rosen [9] described techno-stress as any negative impact on attitudes, thoughts, behaviors, or body physiology caused either directly or indirectly by using technology. Techno-stress is stress from excessive amounts of information and the inability to process it for people who are good at information technology and psychological pressure from the difficulty of adapting to new information technology, which is a symptom that people working in information technology suffer from.

\subsection{Causes and Outcomes of Techno-Stress}

Hudiburg [10] argued that techno-stress occurs when there is not an adequate coping method for new technologies such as information technology, defining techno-stress as a pathological response to information technology. Ayyagari et al. [11] described technostress as psychological incompetence for individuals who cannot handle information technology effectively. Ragu-Nathan et al. [12] implied that techno-stress results from 
managers' dependence on information technology, differences in job knowledge, user level differences, and cultural changes in the work environment depending on new information technology. Information system access can be allowed through information and communications such as mobile computing, network, and business processing systems and can be shared with others in real time without location limitations. Techno-stress can be created from coping with and reacting to information. They identified five sub-factors for the concept of techno-stress by conducting factor analysis. "Techno-overload" describes situations where ICTs force users to work faster and longer. "Techno-invasion" describes the invasive effect of ICTs in terms of creating situations where users can potentially be reached anytime, employees feel the need to be constantly "connected," and there is blurring between work-related and personal contexts. "Techno-complexity" describes situations where the complexity associated with ICTs makes users feel inadequate as far as their skills are concerned and forces them to spend time and effort in learning and understanding various aspects of ICTs. "Techno-insecurity" is associated with situations where users feel threatened about losing their jobs because of a new ICT replacing them or to other people who have a better understanding of the ICT. "Techno-uncertainty" refers to contexts where continuing changes and upgrades in an ICT unsettle users and create uncertainty for them, in that they must constantly learn and educate themselves about new ICTs. Schellhammer et al. [13] defined five causes of techno-stress: the poor condition of always-on access, lack of mobile information technology or cooperation tools requiring multitasking, the lack of new information technology for constant competitiveness and employees' psychological pressure to adapt to it, increasing ambiguity about the requirements of work and stress for continuously updating information technology, and customization of most information technology products to become useful tools but no consideration for users' convenience. Most businesses coordinate and control their internal and external environments and employees using information technology and information systems. Information technology can increase work efficiency but also cause negative factors such as work overload, personal life invasion, and job insecurity. Given that information technology is a work circumstance, techno-stress is one of the other types of stress negatively affecting employees' performance. Techno-stress, a modern disease of adaptation caused by an inability to cope with the new computer technologies healthily, brings employees' business activities to an abnormal state. Salanova et al. [14] explained that techno-stress from the limitation caused in the procedure of using information technology can reduce work performance.

\subsection{Counter-Productivity}

Fox et al. [15] defined counter-productivity as a behavior that is intended to have a detrimental effect on organizations and their members. It can include overt acts such as aggression and theft or more passive acts, such as purposely failing to follow instructions or doing work incorrectly. Spector and Fox [16] described counterproductive work behavior as anti-social behavior, delinquency, and deviance, explaining it as an opposing concept to organizational citizenship behavior, which is the behavior of employees to improve organizational performance voluntarily without any compensation. Chang and Smithikrai [17] described counterproductive work behavior as a behavior that threatens employees' happiness and planned behavior that violates organizational norms. Gruys and Sackett [18] considered counterproductive work behavior as an individual's abnormal behavior that negatively affects the individual's performance or organizational outcome. Counterproductive work behavior refers to all types of biased behavior that hurts organizational performance, which is a potentially undesirable behavior that negatively affects both the organization and its members. Han [19] defined counterproductive work behavior as a destructive behavior that harms the organization and its members, including sabotage in the workplace, wastes of time and raw materials, contaminating the workplace, and withdrawal behavior. Kang et al. [20] described counterproductive work behavior as all behaviors that violate organizational norms and Yoon and Ha [21] defined it as deviance 
in production and deviant behavior such as deliberate avoidance of work, intentional lateness or absence, misuse, and theft of corporate assets. Oh and Yoon [22] presented that deviation behavior and counterproductive work behavior are similar concepts, explaining that deviation behavior and counterproductive work behavior deliberately damage an organization. This study defined counterproductive work behavior as the intentional behavior of an employee which affects the organization and its members in a negative way against the interests of the organization.

The concept of innovation resistance first came from Sheth's [23] study on diffusion and acceptance. Ram [24] explained that failure of a company's new product or service stems from consumer resistance, defining innovation resistance as resistance to changes in existing satisfaction with products and services. Innovation resistance is not the opposite of acceptance or diffusion, but rather a process that comes from the group's attitudes toward innovative technologies. Laukkanen et al. [25] defined innovation resistance as the conflict between the behavior to keep the existing state and the external intention to change it. Kotter [26] conceptualized it as the propensity to keep the current situation for rejection of change. The psychological state of an individual influences individual characteristics and causes innovation resistance, presenting determinants of innovation resistance like relative advantages, adaptedness, complexity, testability, communicability, perceived risk, and personal disposition. Relative advantages refer to the economic or monetary value obtained through change. Adaptedness is the degree to which it meets the current value or experience and needs of the product. Complexity is the structural mess of a product or service. Communicability refers to the degree to which a change in a product or service is delivered to others. Perceived risk refers to the physical, functional, and psychological risk for selecting change. Personal disposition is an attitude or propensity to respond to change.

The causes of innovation resistance are divided into individual and organizational dimensions. The causes of innovation resistance at the individual dimension include perceived habits, perceived risks of individuals, the threat of results, loss of control, disruption of daily life, an overload of work, confidence, forced change, investment in the speed of change, congestion from changes in the organizational size, fear of habit change, need for safety, risk of declined economic income, the fear of the unknown caused by the change, guilt from a selective information processing, following routines, sensory reactions, short-term thinking, and cognitive rigidity [27]. On the other hand, the causes of innovation resistance at the organizational dimension include sunk costs, information constraints of decision-makers, political constraints of interests, organizational tradition and history, inertia and conflict of interests, threats to organizational expertise, limited resources, collective and structural inertia, limited views of change, information deficits, inappropriate resource allocation, dissatisfaction with the change, lack of leadership, and distrust of the organization [28].

\subsection{Relationship between Techno-Stress and Counter-Productivity}

The inability to cope with the introduction and use of new technologies has a negative relationship with physical and psychological burnout. An increase in workload from technology overload causes dissatisfaction, fatigue, insecurity, innovation resistance, and overwork, leading to job burnout [29]. Techno-stress from the increasing emotional stress of employees who have a poor adaptation to changes in information systems degrades job satisfaction and productivity with counterproductive work behavior and work condition [30]. Changes in the internal and external environments of businesses forced by the development of information technology are compelling companies to modify their operational strategies, in which techno-stress imposes increased workload, decreases employees' satisfaction, and enhances cognitive performance for innovative and committed production activity [31-33]. There is a negative relationship between techno-stress and job performance in that incomplete exhaustion of techno-stress leads to deterioration of the individual's innovative work, negatively affecting employees' positive behavior for improving organizational performance [34]. Techno-stress brings out absenteeism and turnover relating to 
change resistance and commitment in production activity, which reduces productivity [35]. Existing studies highlight stress management to improve organizational performance by enhancing employees' satisfaction of participation in the production process, accelerating organizational commitment, and increasing innovation and productivity [36].

The literature on techno-stress is likely to concentrate on counterproductive work behavior as a detriment of stress $[37,38]$. Counterproductive work behavior includes disruptive behavior, wasting time and materials, hostile behavior toward others, and abnormal behavior at work. As techno-stress accumulates, it is possible to consider turnover in the long term in addition to emotional instability including hostility to others or deviations such as sabotage or absenteeism [39]. Unlike personal or organizational separation in the short-term as counterproductive work behavior, it results in rejecting change over the long term, interrupting innovation through the introduction of ICT, or turning down new work.

\subsection{Moderating Effects of Self-Efficacy and Technical Support}

Studies on self-efficacy were conducted in the field of psychology for the first time, starting discussions on environmental and personal factors that can lead to changes in human behavior. Self-efficacy is an individual element used to predict and change human behavior [40]. Self-efficacy is confidence in one's ability or competence. Wood and Bandura [41] defined self-efficacy as an individual's belief that they can trigger a set of actions required to meet resources given situational demands and create motivation. Kanfer [42] defined self-efficacy as cognitive judgments on a plan necessary to achieve goals and behavioral ability including motivation, resources, and beliefs required to perform tasks. These conceptual definitions rely on the view that individuals' psychological choices are not automatically adjusted by an individual's internal tendencies or external stimuli but are determined by interactions through intentional self-regulation. Self-efficacy has an impact on human behavior [43] when making something new or innovative and improving performance in terms of the purposes of individuals or organizations. Individuals set targets with high difficulty levels at high levels of self-efficacy and relatively easy targets at low levels, which means that individuals have different perceptions of risks and challenges that can harm or encourage employees' innovation and committed work behavior depending on their level of self-efficacy. Hackman and Oldham [44] insisted that employees with high self-efficacy are more likely to feel security and confidence in a job with the power to make independent judgments or decisions and show positive and psychological behavior and results, compared to those with low levels of self-efficacy. Self-efficacy refers to the characteristics that influence individual achievement and fulfillment of successful work [45]. Self-efficacy can be built through experiences and processes repeatedly skilled for a specific task and create expectations and beliefs about one's abilities, self-regulation, and task challenges [46].

Organizational support including technical support in the service industries, including IT, can create value through the work satisfaction of members of the organization and increase users' satisfaction to challenge new and innovative work change [47]. Meier and Hicklin [48] suggested that support in terms of education of new working technology and motivation for commitment to work at the organizational level has positive effects on employees. The rewards from the organization and the employees' contributions to the organization are proportional. However, if there is a large difference, they would feel stress. If the utility of incentives through organizational support is higher than that of the members' contributions, the stress becomes reduced. The organizational balance theory focuses on the balance between organizational rewards and member contributions. To create a positive effect, they use the concept of inducement for support at the organizational level, including education and training, technical support, and compensation or wage as incentives. From the research on support and organizational commitment at the corporate level, in particular, technical support at the organizational level can surge employees' commitment to their work and intention of trying innovative work process. Korunka et al. [49] and Charkhabi [50] argued that if the organizational support for technical education is acti- 
vated, the organizational commitment is strengthened and the stress related to technology use decreases. From a study on the determinants of the turnover intention of domestic IT professionals, the satisfaction of technology education for new information systems reduces techno-stress. Kim and Kang [51] suggested that various organizational support for technology competency development (education of new technologies, support for the utilization of new technologies, new technology development activities) reduces techno-stress and affects turnover through a survey on the current status and turnover of IT personnel. Kim and Kim [52] determined that participation promotion and technical support play a moderating effect between techno-stress and job satisfaction. Ahmad et al. [53] found that promotion of utilization ability and participation in information technology and technical support have relationships with organizational commitment and techno-stress.

\section{Methods}

\subsection{Research Model}

This study aimed to investigate the relationship between techno-stress and counterproductivity, testing the moderating effect of mitigation factors. Techno-stress is a multiconceptualized rather than a single-dimension concept. It suggests that techno-stress consists of techno-overload, techno-invasion, techno-complexity, techno-insecurity, and techno-uncertainty. From the positive aspect of stress, job satisfaction and organizational commitment are the most representative outcome variables, but from the negative aspect, stress itself has a negative relationship with organizational performance. Physical and psychological burnout, feelings of helplessness, counterproductive work behavior, and innovation resistance are negative outcomes caused by stress. Mitigation factors include self-efficacy at the individual level and technical support such as education and training at the level of organizations. We set up the research model to investigate the effects of techno-stress on counter-productivity and the moderating effects of mitigation factors, as shown in Figure 1.

\section{Mitigation factors}

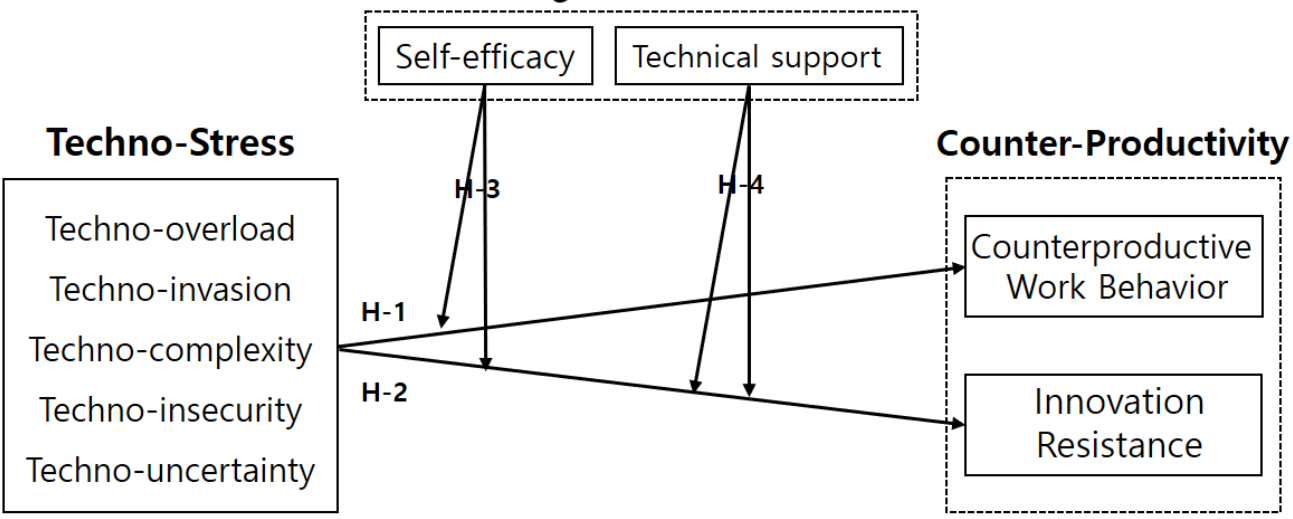

Figure 1. Research model.

\subsection{Research Hypothesis}

Techno-stress has a negative relationship with organizational performance. Employees can create counterproductive work behaviors such as sabotage, waste of time and materials, hostile behavior toward others, and deviant behaviors in the workplace, which are abnormal work behaviors directly caused by stress. As employees' techno-stress accumulates, they can have hostile aggressions toward others and commit organizational deviation behaviors such as sabotage or absenteeism because of emotional instability. Unlike individual and group deviations, counterproductive work behaviors can hinder innovation expected in introducing ICT technology or reject new work and negatively impact change across the organization. This is a phenomenon in which control is lost due to being overworked and is also complicated by new ICT technologies. In addition, employees are stuck due to 
cognitive rigidity or trying to keep their routines. Organizations are resistant to innovation with a limited view of change and collective and structural inertia. Employees oppose individually and collectively to the demands of changes in the current task from the adoption of new technologies. Based on previous literature reviews, the following two hypotheses were developed to investigate the relationship between techno-stress, counterproductive work behavior, and innovation resistance.

H1. Techno-stress is positively associated with counterproductive work behavior (CWB).

H2. Techno-stress is positively associated with innovation resistance.

Techno-stress causes counter-productivity, but it can be degraded by individual competencies or organizational management. In terms of individual competencies, self-efficacy can reduce the counter-productivity caused by techno-stress, i.e., employees can get confidence in new work by enhancing their ability to adapt to new technologies, which alleviates techno-stress and takes care of counterproductive work behavior. Even with high technostress, employees can refrain from counterproductive work behavior and spur innovation through challenges once they can achieve new work goals. Organizations can exterminate counterproductive work behavior if they give appropriate financial compensation as an additional benefit for techno-stress or technical support such as education and training for new technologies. Incentives to prevent job turnover caused by stress. Based on previous literature reviews, the following two hypotheses were developed to test the moderating effects of self-efficacy and technical support on the causal relationship between techno-stress and counter-productivity.

H3. The association between techno-stress and counter-productivity is moderated by self-efficacy.

H4. The association between techno-stress and counter-productivity is moderated by technical support.

\subsection{Survey Design-Participants, Procedure, Measures, and Data Analysis \\ 3.3.1. Participants}

Participants in this study were employees both in IT and non-IT industries. IT industries use and provide information and information systems based on computers; non-IT ones belong to manufacturers, service companies, and public agencies. The percentage of IT sectors across the overall proportion of the industry is significantly low, but since this study focused on techno-stress caused by ICT, the ratio of employees in the IT sector was relatively high in the number of survey objects.

\subsubsection{Procedure}

Procedure for the survey was conducted to a sample size of 300 in the IT industry and 400 in non-IT industries using a convenient sampling method. The survey was divided into venture and non-venture companies to measure the effect of the introduction of new technology on techno-stress: 150 in venture companies and 550 in non-venture companies. We conducted a prior test to improve the reliability and validity of the measurement tool targeting 100 people working in five businesses from 3 to 10 January in 2019 before the survey. We used a mail survey to collect data after explaining the purpose of the research in the practices for around two months from 1 February to 31 March 2019. All invalid data were excluded, and 620 valid data were utilized for this study.

\subsubsection{Measures}

Measures for this study were modified based on the questionnaire items used in previous studies. According to Tarafdar et al. [3], techno-stress is defined as a state caused by a lack of effort of individuals and organizations to adapt to operation due to the introduction of new technology (information technology).

Techno-stress consists of five factors: techno-overload, techno-invasion, technocomplexity, techno-insecurity, and techno-uncertainty. They are measured on a Likert 5 -point scale from 1 (strongly disagree) to 5 (strongly agree). An example of the included 
items is "The degree to which new technologies are required to do things faster." Cronbach's $\alpha$ for this scale ranged between 0.77 and 0.80 .

Counter-productivity is defined as counterproductive work behavior by Fox et al. [15]. It consists of counterproductive work behavior (CWB) and innovation resistance. Five items for counterproductive work behavior are measured on a Likert 5-point scale from 1 (strongly disagree) to 5 (strongly agree). An example of the included items is "Spread bad rumors about a coworker." Cronbach's $\alpha$ for this scale was 0.85 .

Innovation resistance as a factor of counter-productivity is derived from the studies of Ram [24] and Sheth [23]. Their scales consist of nine items. All items are rated on a five-point Likert scale from 1 (strongly disagree) to 5 (strongly agree). An example of the included items is "Stick to existing technology over new technology." Cronbach's $\alpha$ for this scale was 0.87 .

Self-efficacy is defined by Jones [1] and Wood and Bandura [43], consisting of seven items to be measured. All items are rated on a five-point Likert scale from 1 (strongly disagree) to 5 (strongly agree). An example of the included items is "Confident in my ability to do the task." Cronbach's $\alpha$ for this scale was 0.89 .

Technical support is derived from Korunka et al. [50] for five measurement items on a Likert 5-point scale from 1 (strongly disagree) to 5 (strongly agree). An example of the included items is "The company provides training on the introduction and use of new technologies." Cronbach's $\alpha$ for this scale was 0.88 .

\subsubsection{Data}

Data analysis in the study was conducted using SPSS 22 to analyze the data collected. Descriptive statistics were obtained to explore the demographic characteristics. Validity tests using confirmatory factor analysis were used to verify research variables. The correlation analysis utilizes the correlations between variables and Cronbach's alpha used for reliability analysis. Multiple regression analysis with an ordinary least square (OLS) method for moderating analysis was used to test the hypotheses and necessary statistical procedures and the diagram deployed [51].

\section{Results}

\subsection{Demographic Characteristics}

As can be seen in Table 1, of the total 620 respondents, $243(39.2 \%)$ were in the IT industry, $109(17.6 \%)$ were in the manufacturing industry, $118(19.0 \%)$ were in the service industry, $113(18.2 \%)$ were in public organizations, and 37 (6.0\%) were in others. As for venture companies, 119 employees $(19.2 \%)$ were employed in venture companies, and 501 $(80.8 \%)$ were in non-venture companies. In terms of labor unions, $152(24.5 \%)$ were in a labor union, and $468(75.5 \%)$ were not.

Table 1. Characteristics of research company $(\mathrm{N}=620)$.

\begin{tabular}{cccc}
\hline Category & Value & Frequency & $\%$ \\
\hline Industry & IT Industry & 243 & 39.2 \\
& Non-IT Manufacture & 109 & 17.6 \\
& Non-IT Service & 118 & 19.0 \\
& Non-IT Public Affair & 150 & 24.2 \\
\hline \multirow{2}{*}{ Business Type } & Venture & 119 & 19.2 \\
& Non-Venture & 501 & 80.8 \\
\hline \multirow{2}{*}{ Union } & Labor Union & 152 & 24.5 \\
& No Labor Union & 468 & 75.5 \\
\hline
\end{tabular}

From Table 2, respondents in the sample were between 20 and 59 years of age, $70.0 \%$ were male, $50.5 \%$ were married, $94.7 \%$ had attained more than a college qualification, and $48.9 \%$ were the street level of employees. It is worthy to note that the respondents tended 
to be a little bit old and more educated. In particular, the response rate of men was higher than the one of women.

Table 2. Participants' characteristics $(\mathrm{N}=620)$.

\begin{tabular}{|c|c|c|c|}
\hline \multicolumn{2}{|c|}{ Category Value } & \multirow{3}{*}{$\begin{array}{c}\text { Frequency } \\
465 \\
255\end{array}$} & \multirow{3}{*}{$\begin{array}{c}\mathbf{\%} \\
70.0 \\
25.0\end{array}$} \\
\hline & 1 = Male & & \\
\hline Gender & $2=$ Female & & \\
\hline Age & \multicolumn{3}{|c|}{ Minimum $=20$ years, Maximum $=59$ years } \\
\hline \multirow[t]{2}{*}{ Marital Status } & $\begin{array}{c}1=\text { Single, } \text { Divorced }, \\
\text { Windowed }\end{array}$ & 307 & 49.5 \\
\hline & $2=$ Married & 313 & 50.5 \\
\hline \multirow{3}{*}{ Education } & $\begin{array}{c}1=\text { Less than the } \\
\text { Level of High School }\end{array}$ & 33 & 5.3 \\
\hline & $2=$ College & 471 & 76.0 \\
\hline & $3=$ Graduate School & 116 & 18.7 \\
\hline \multirow{5}{*}{ Position } & 1 = Employees & 303 & 48.9 \\
\hline & $2=$ Senior Assistants & 145 & 23.4 \\
\hline & $3=$ Section Chiefs & 118 & 19.0 \\
\hline & 4 = Managers & 43 & 6.9 \\
\hline & $5=$ Executives & 11 & 1.8 \\
\hline
\end{tabular}

\subsection{Validity Tests and Reliability Test}

This study utilized a confirmatory factor analysis and Cronbach's alpha to test the validity and reliability of construct measurement scales. The study conducted a confirmatory factor analysis to verify the validity of the measurement tool using the covariance matrix. Table 3 presents all relevant values of $\chi^{2}=89.843(\mathrm{df}=17, p<0.001)$, $\mathrm{RMR}=0.022$, $\mathrm{CFI}=0.912, \mathrm{NFI}=0.895, \mathrm{GFI}=0.941$, and AGFI $=0.875$, which means that this model has good fitness. The path coefficients of the variables measuring each study concept are all significant.

Table 3. Confirmatory factor analysis and Cronbach's alpha values.

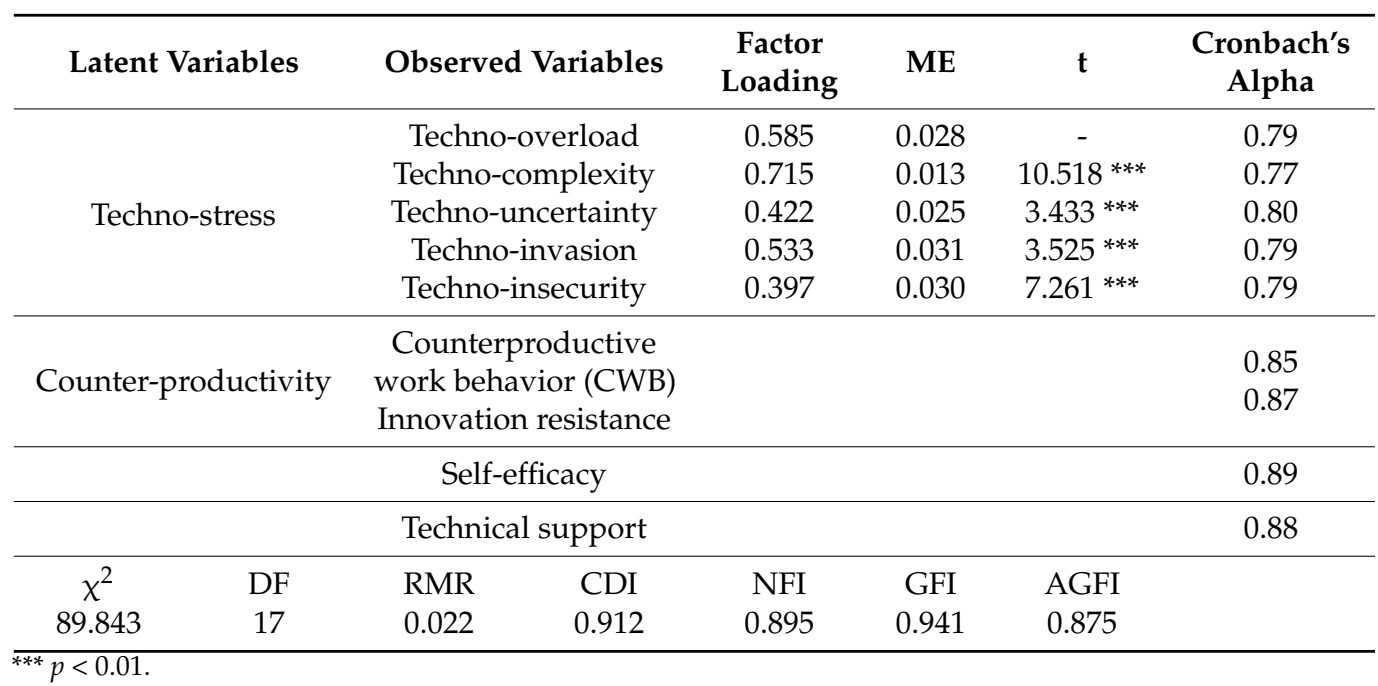

For reliability testing, Cronbach's alpha was utilized. If Cronbach's alpha is over 0.7, reliability meaning internal consistency is secured. In Table 4, Cronbach's alpha values ranged from 0.79 to 089 , exceeding the minimum threshold of 0.7 . Composite reliability should be greater than the threshold of 0.7 to be adequate in the latent variable of technostress. All related reliabilities of the latent variables and observed variables have values higher than 0.7. Thus, reliability for all variables in this study is secured. 
Table 4. Correlation among techno-stress, moderation, and counter-productivity.

\begin{tabular}{|c|c|c|c|c|c|c|c|c|c|}
\hline \multirow{2}{*}{ Items } & \multicolumn{5}{|c|}{ Techno-Stress } & \multicolumn{2}{|c|}{ Moderation } & \multicolumn{2}{|c|}{$\begin{array}{c}\text { Counter- } \\
\text { Productivity }\end{array}$} \\
\hline & T1 & $\mathrm{T} 2$ & T3 & $\mathrm{T} 4$ & T5 & M1 & M2 & $\mathrm{C} 1$ & $\mathrm{C} 2$ \\
\hline T1 & 1 & & & & & & & & \\
\hline T2 & $\begin{array}{l}0.551^{* *} \\
0.539 * *\end{array}$ & $\begin{array}{c}1 \\
0.603 \text { ** }\end{array}$ & 1 & & & & & & \\
\hline $\begin{array}{l}13 \\
\mathrm{~T} 4\end{array}$ & 0.459 ** & 0.613 ** & 0.642 ** & 1 & & & & & \\
\hline $\begin{array}{l}14 \\
\mathrm{~T} 5\end{array}$ & 0.458 ** & 0.409 ** & $0.481^{* *}$ & $0.481 * *$ & 1 & & & & \\
\hline M1 & -0.075 & $-0.107^{* *}$ & -0.019 & -0.072 & -0.036 & 1 & & & \\
\hline M2 & $-0.208^{* *}$ & $-0.392 * *$ & $-0.332^{* *}$ & $-0.486^{* *}$ & $-0.120 * *$ & $0.232 * *$ & 1 & & \\
\hline $\mathrm{C} 1$ & $0.175^{* *}$ & $0.240^{* *}$ & $0.170^{* *}$ & $0.336^{* *}$ & $0.290^{* *}$ & $-0.254 * *$ & $-0.452 * *$ & 1 & \\
\hline $\mathrm{C} 2$ & $0.133^{* *}$ & $0.100 *$ & 0.046 & 0.021 & $0.125 * *$ & $-0.462 * *$ & $-0.254^{* *}$ & $-0.160 * *$ & 1 \\
\hline
\end{tabular}

T1: techno-overload, T2: techno-invasion, T3: techno-complexity, T4: techno-insecurity, T5: techno-uncertainty M1: self-efficacy, M2: technical support, C1: counterproductive work behavior, C2: innovation resistance. ${ }^{*} p<0.05,{ }^{* *} p<0.01$

\subsection{Correlation Analysis}

Table 4 shows the correlation coefficients between techno-stress, mitigating factors, and anti-productivity. Among the constructs of techno-stress, techno-invasion correlates with self-efficacy at a significance level of 0.01 , but the rest of them do not have a statistically significant correlation. Technical support has negative correlations with techno-stress at a significance level of 0.01 . All the techno-stress constructs have a significantly positive correlation with counterproductive work behavior at a significance level of 0.01 . Techno-overload, techno-invasion, and techno-uncertainty have positive correlations with innovation resistance. Self-efficacy and technical support have negative correlations with counterproductive work behavior at a significance level of 0.01 and positive correlations with innovation resistance at a significance level of 0.01 .

Techno-stress correlates with the same direction with counter-productivity, which means that the higher the techno-stress, the stronger the worker's avoidance from work. This effect is the same as the detriment of stress from working conditions. Self-efficacy and technical support have a negative correlation with techno-stress, which means that selfefficacy and technical support mitigate the detrimental effects arising from techno-stress by self-control in the individual dimension and organizational support in organizational one.

\subsection{Hypotheses Test}

\subsubsection{Interaction between Techno-Stress and Self-Efficacy}

As seen in Table 5 and Figure 2, in step 1, the techno-stress variables are as follows: techno-complexity $(\beta=0.162)$, techno-invasion $(\beta=0.318)$, and techno-insecurity $(\beta=0.237)$ are positively related to $C W B$; while techno-overload $(\beta=0.129)$, technocomplexity $(\beta=0.099)$, techno-invasion $(\beta=0.087)$, and techno-insecurity $(\beta=0.140)$ are related to innovation resistance. Self-efficacy $(\beta=-0.189 /-0.406)$ has negative impacts on CWB and innovation resistance in step 2. For step 3, regarding the testing moderation of self-efficacy for the relationships between techno-stress and CWB and innovation resistance, the interaction between techno-overload and self-efficacy $(\beta=-0.084)$, the interaction between techno-invasion and self-efficacy $(\beta=-0.153)$, and the interaction between technoinsecurity and self-efficacy $(\beta=-0.082)$ negatively impact $C W B$, whereas the interaction between techno-complexity and self-efficacy $(\beta=-0.082)$ negatively impacts innovation resistance. The $R^{2}$ values increase from $0.187 / 0.054$ in step 1 to $0.252 / 0.221$ in step 3 .

This study tested the significance of moderating variables using bootstrapping. As a result, $R^{2}$ is $20.5 \%$, and the model fit is F-value $=19.022(p<0.001)$. The moderating effects can be statistically significant because the upper and lower bootstrap coefficients do not contain a value of 0 within the confidence interval. 
Table 5. Ordinary least square (OLS) regression results testing moderation of Techno-stress $\times$ Self-efficacy.

\begin{tabular}{|c|c|c|c|c|c|c|c|c|}
\hline \multirow{2}{*}{ Variables } & \multicolumn{4}{|c|}{ CWB } & \multicolumn{4}{|c|}{ Innovation Resistance } \\
\hline & Beta & SE & $\mathbf{t}$ & $p$ & Beta & SE & $\mathbf{t}$ & $p$ \\
\hline \multicolumn{9}{|l|}{ Step 1} \\
\hline Techno-overload & 0.063 & 0.037 & 1.702 & 0.093 & 0.129 & 0.040 & 3.225 & 0.001 \\
\hline Techno-complexity & 0.162 & 0.040 & 4.050 & 0.000 & 0.099 & 0.039 & 2.538 & 0.013 \\
\hline Techno-uncertainty & 0.018 & 0.038 & 0.473 & 0.632 & 0.005 & 0.037 & 0.0135 & 0.905 \\
\hline Techno-invasion & 0.318 & 0.036 & 8.833 & 0.000 & 0.087 & 0.038 & 2.289 & 0.031 \\
\hline Techno-insecurity & 0.237 & 0.039 & 6.076 & 0.000 & 0.140 & 0.041 & 3.414 & 0.001 \\
\hline & \multicolumn{4}{|c|}{$\mathrm{F}=27.173, p<0.01, \mathrm{R}^{2}=0.187$} & \multicolumn{4}{|c|}{$\mathrm{F}=6.660, p<0.01, \mathrm{R}^{2}=0.054$} \\
\hline Step 2 & & & & & & & & \\
\hline Techno-overload & 0.081 & 0.037 & 2.214 & 0.027 & 0.089 & 0.037 & 2.419 & 0.016 \\
\hline Techno-complexity & 0.194 & 0.037 & 5.258 & 0.000 & 0.029 & 0.037 & 0.780 & 0.436 \\
\hline Techno-uncertainty & 0.023 & 0.036 & 0.631 & 0.528 & 0.006 & 0.037 & 0.171 & 0.864 \\
\hline Techno-invasion & 0.299 & 0.037 & 8.156 & 0.000 & 0.046 & 0.037 & 1.237 & 0.217 \\
\hline Techno-insecurity & 0.246 & 0.036 & 6.739 & 0.000 & 0.121 & 0.037 & 3.284 & 0.001 \\
\hline \multirow[t]{2}{*}{ Self-efficacy } & -0.189 & 0.037 & -5.052 & 0.000 & -0.406 & 0.038 & -10.785 & 0.000 \\
\hline & \multicolumn{4}{|c|}{$\mathrm{F}=27.862, p<0.01, \mathrm{R}^{2}=0.221$} & \multicolumn{4}{|c|}{$\mathrm{F}=26.022, p<0.01 ; \mathrm{R}^{2}=0.210$} \\
\hline \multicolumn{9}{|l|}{ Step 3} \\
\hline Techno-overload & 0.045 & 0.039 & 1.169 & 0.243 & 0.086 & 0.039 & 2.172 & 0.030 \\
\hline Techno-complexity & 0.168 & 0.037 & 4.572 & 0.000 & 0.037 & 0.038 & 0.984 & 0.326 \\
\hline Techno-uncertainty & 0.025 & 0.037 & 0.664 & 0.507 & 0.002 & 0.038 & 0.064 & 0.949 \\
\hline Techno-invasion & 0.278 & 0.037 & 7.412 & 0.000 & 0.053 & 0.038 & 1.396 & 0.163 \\
\hline Techno-insecurity & 0.255 & 0.037 & 6.963 & 0.000 & 0.125 & 0.037 & 3.342 & 0.001 \\
\hline Self-efficacy & -0.229 & 0.039 & -5.889 & 0.000 & -0.408 & 0.040 & -10.288 & 0.000 \\
\hline $\begin{array}{l}\text { Techno-overload } \times \\
\text { Self-efficacy }\end{array}$ & -0.084 & 0.030 & -2.760 & 0.006 & -0.001 & 0.031 & -0.020 & 0.984 \\
\hline $\begin{array}{l}\text { Techno-complexity } \times \\
\text { Self-efficacy }\end{array}$ & -0.034 & 0.029 & -1.174 & 0.241 & -0.082 & 0.029 & -1.794 & 0.005 \\
\hline $\begin{array}{l}\text { Techno-uncertainty } \times \\
\text { Self-efficacy }\end{array}$ & -0.024 & 0.039 & -0.616 & 0.538 & -0.003 & 0.040 & -0.072 & 0.943 \\
\hline $\begin{array}{l}\text { Techno-invasion } \times \\
\text { Self-efficacy }\end{array}$ & -0.153 & 0.037 & -4.110 & 0.000 & -0.015 & 0.038 & -0.391 & 0.696 \\
\hline \multirow{2}{*}{$\begin{array}{c}\text { Techno-insecurity } \\
\text { Self-efficacy }\end{array}$} & -0.082 & 0.039 & -1.781 & 0.036 & -0.034 & 0.040 & -0.863 & 0.389 \\
\hline & \multicolumn{2}{|c|}{$\mathrm{F}=17.844, p<0.01, \mathrm{R}^{2}=0.252$} & & & \multicolumn{4}{|c|}{$\mathrm{F}=15.055, p<0.01 ; \mathrm{R}^{2}=0.221$} \\
\hline
\end{tabular}
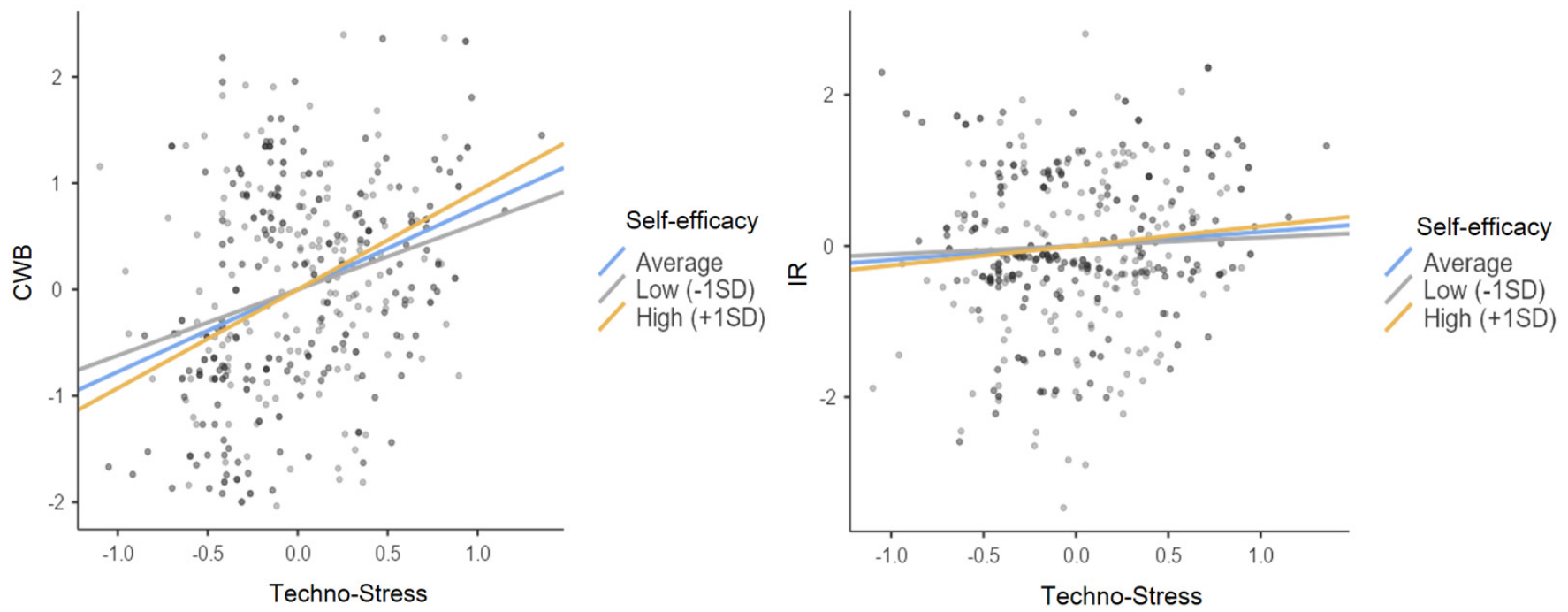

Figure 2. Interaction between techno-stress and self-efficacy. 


\subsubsection{Interaction between Techno-Stress and Technical Support}

As seen in Table 6 and Figure 3, technical support $(\beta=-0.340 /-0.229)$ has negative impacts on CWB and innovation resistance in step 2. In step 3, the interaction between techno-insecurity and technical support $(\beta=-0.075)$ negatively impacts $C W B$, whereas the interactions between techno-overload and technical support $(\beta=-0.197)$, technouncertainty and technical support $(\beta=-0.098)$, and techno-invasion and technical support ( $\beta=-0.088$ ) have negative influences on innovation resistance. The values of $R^{2}$ in the relationship between techno-stress and technical support and CWB increase by 0.96 , a change in $R^{2}$ between step 1 and step 3 . For innovation resistance, the $R^{2}$ value in step 1 is 0.054 and 0.156 in step 3, which shows the growth of $R^{2}$ as evidence of moderating effects in our research model.

Table 6. OLS regression results testing moderation of Techno-stress $\times$ Technical Support.

\begin{tabular}{|c|c|c|c|c|c|c|c|c|}
\hline \multirow{2}{*}{ Variables } & \multicolumn{4}{|c|}{ CWB } & \multicolumn{4}{|c|}{ Innovation Resistance } \\
\hline & Beta & SE & $\mathbf{t}$ & $p$ & Beta & SE & $t$ & $p$ \\
\hline \multicolumn{9}{|l|}{ Step 1 (same as Table 5) } \\
\hline Techno-overload & 0.036 & 0.035 & 1.027 & 0.305 & 0.146 & 0.040 & 3.701 & 0.000 \\
\hline Techno-complexity & 0.063 & 0.037 & 1.692 & 0.091 & 0.165 & 0.042 & 3.971 & 0.000 \\
\hline Techno-uncertainty & 0.080 & 0.036 & 2.207 & 0.028 & 0.037 & 0.040 & 0.915 & 0.361 \\
\hline Techno-invasion & 0.171 & 0.040 & 4.284 & 0.000 & 0.012 & 0.044 & 0.275 & 0.784 \\
\hline Techno-insecurity & 0.251 & 0.035 & 7.108 & 0.000 & 0.130 & 0.039 & 3.294 & 0.001 \\
\hline Technical Support & -0.340 & 0.043 & -7.994 & 0.000 & -0.229 & 0.047 & -4.821 & 0.000 \\
\hline \multicolumn{5}{|c|}{$\mathrm{F}=35.714, p<0.01, \mathrm{R}^{2}=0.267$} & \multicolumn{4}{|c|}{$\mathrm{F}=9.634, p<0.01, \mathrm{R}^{2}=0.090$} \\
\hline $\begin{array}{c}\text { Step } 3 \\
\text { Techno-overload }\end{array}$ & 0.051 & 0.036 & 1.423 & 0.155 & 0.111 & 0.039 & 2.844 & 0.005 \\
\hline Techno-complexity & 0.078 & 0.038 & 2.080 & 0.038 & 0.147 & 0.041 & 3.591 & 0.000 \\
\hline Techno-uncertainty & 0.084 & 0.037 & -2.288 & 0.023 & 0.036 & 0.040 & 0.907 & 0.365 \\
\hline Techno-invasion & 0.179 & 0.040 & 4.452 & 0.000 & 0.005 & 0.044 & 0.118 & 0.906 \\
\hline Techno-insecurity & 0.246 & 0.035 & 6.947 & 0.000 & 0.121 & 0.038 & 3.161 & 0.002 \\
\hline Technical Support & -0.339 & 0.044 & -7.683 & 0.000 & -0.260 & 0.048 & 5.424 & 0.000 \\
\hline $\begin{array}{l}\text { Techno-overload } \times \\
\text { Technical Support }\end{array}$ & -0.017 & 0.030 & -0.573 & 0.567 & -0.197 & 0.032 & -6.079 & 0.000 \\
\hline $\begin{array}{c}\text { Techno-complexity } \times \\
\text { Technical Support }\end{array}$ & -0.049 & 0.034 & -1.436 & 0.151 & -0.002 & 0.037 & -0.048 & 0.962 \\
\hline $\begin{array}{l}\text { Techno-uncertainty } \times \\
\text { Technical Support }\end{array}$ & -0.053 & 0.037 & -1.426 & 0.155 & -0.098 & 0.040 & -2.443 & 0.015 \\
\hline $\begin{array}{l}\text { Techno-invasion } \times \\
\text { Technical Support }\end{array}$ & -0.054 & 0.038 & -1.436 & 0.152 & -0.088 & 0.041 & -2.152 & 0.032 \\
\hline \multirow{2}{*}{$\begin{array}{l}\text { Techno-insecurity } \times \\
\text { Technical Support }\end{array}$} & -0.075 & 0.035 & -2.165 & 0.031 & -0.035 & 0.038 & -0.935 & 0.350 \\
\hline & \multicolumn{4}{|c|}{$\mathrm{F}=20.939, p<0.01, \mathrm{R}^{2}=0.283$} & \multicolumn{4}{|c|}{$\mathrm{F}=9.798, p<0.01, \mathrm{R}^{2}=0.156$} \\
\hline
\end{tabular}
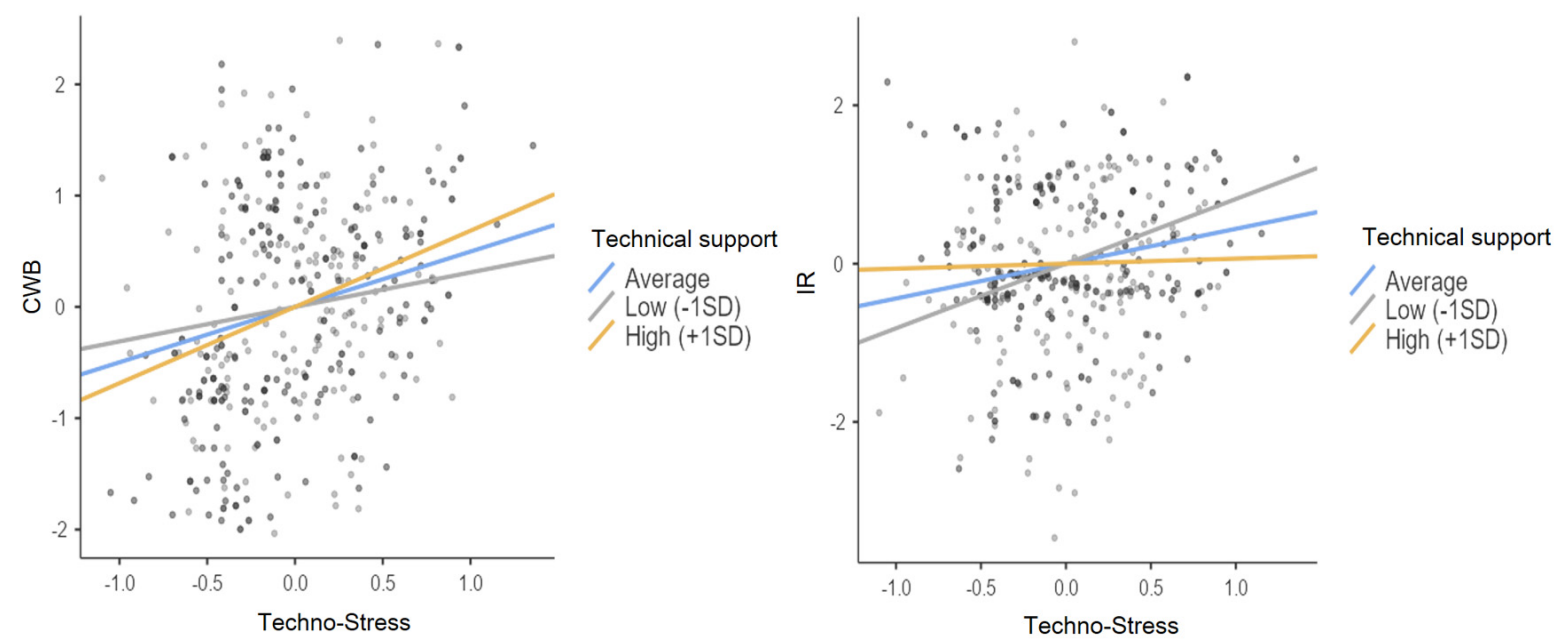

Figure 3. Interaction between techno-stress and technical support. 
This study tested the significance of moderating variables using bootstrapping. As a result, $\mathrm{R}^{2}$ is $22.2 \%$, and the model fit is $\mathrm{F}$-value $=21.389(p<0.001)$. The moderating effects can be statistically significant because the upper and lower bootstrap coefficients do not contain a value of 0 within the confidence interval.

\section{Discussion}

This study tried theoretical approaches to the techno-stress theory through an extension of the traditional stress theory model. The stress theory model focuses on improving organizational effectiveness by stress management. This study is differentiated from previous studies in that it focuses on counterproductive factors such as counterproductive work behavior and innovation resistance. The empirical analysis on the relationship between techno-stress and counter-productivity supports the theoretical model we set up and has value as theoretically complementary evidence for techno-stress. In addition, we have the research achievement that self-efficacy and technical support included in this study have counter-productivity mitigation effects.

This study resulted in some key implications. First, the study tested the detrimental effects of techno-stress that employees experience amid the introduction of new technology. There is a lot of discussion about the changes in existing and new jobs that the Fourth Industrial Revolution can bring, but there is a lack of practical implications for the business world in which new technology may trigger stress for employees as a detrimental effect. Second, we empirically tested whether self-efficacy and technical support can degrade the detrimental effects in the causal structure of techno-stress and counter-productivity. From this test, this study contributes to accumulating evidence for building the theory that self-efficacy and technical support can play roles as moderating variables. Third, effective countermeasures are needed to relieve CWB and innovation resistance caused by techno-stress and maintain productivity. For a short-term period, techno-overload, techno-invasion, techno-insecurity, and techno-uncertainty resulting from new technologies aggravate $\mathrm{CWB}$, which creates sabotages and employee victims and lowers the quality of products. In the long term, since the introduction of new technologies to secure competitiveness can negatively affect productivity, support for long-term service employees and senior workers should start from the preparatory stage for introducing new technologies. When organizations promote innovation through new technologies to strengthen competitiveness, they suffer innovation resistance due to work overload, invasion of privacy, and uncertainty in predicting work. Organizations should develop devices to mitigate the detrimental effects of introducing new technologies to manage these innovation resistances. Fourth, to control counter-productivity such as CWB and innovation resistance due to techno-stress, businesses should have plans to improve self-efficacy to enhance individual competencies and alternatives to provide technical support such as information technology education and train as organizational support. Self-efficacy can alleviate technooverload and techno-insecurity, and technical support for new technologies can relieve techno-uncertainty. The effect of self-efficacy can prevent counterproductive work behavior. When innovation resistance is strong, organizations can reduce resistance by reducing techno-overload, techno-complexity, and techno-insecurity with technical support.

There are some limitations. Given the lack of sufficient research related to this topic, the present study provides several results that may advance the current literature on techno-stress and counter-productivity. However, this study was conducted considering only certain industries. Thus, it is necessary to supplement this research in the context of other industries. Additionally, it is necessary to supplement this study by clarifying the relationships between other related impact factors. In our study, we focused on a certain perspective that does not explore all related factors needed to form a comprehensive theory. Since the study was conducted based only on responses at a specific point in time, there is also a limitation in not being able to verify the results over a long period of time-series data. In the future, we look to fully examine common method variance (CMV) and self-report measures concerning this topic. 


\section{Conclusions}

This study empirically explored the effect of techno-stress on counter-productivity and further identified the moderating effect of self-efficacy and technical support in the relationship between techno-stress and counter-productivity. The findings of the analysis results of this study are as follows.

First, techno-stress has a significant effect on counter-productivity. Techno-overload has a significantly positive impact on CWB. In addition, techno-invasion, techno-insecurity, and techno-uncertainty have positive effects on CWB. When techno-invasion, technoinsecurity, and techno-uncertainty get worse, the detrimental intentional behaviors or behaviors against the legitimate interests of organizations are more likely to arise. Technooverload, techno-invasion, techno-insecurity, and techno-uncertainty affect innovation resistance. Techno-insecurity has a negative effect on innovation resistance, which means that that the higher the techno-insecurity, the lower the resistance behavior by trying to adapt to the current situation. In addition, the influence of techno-uncertainty on innovation resistance is quite strong, which means that changes caused by the introduction of new technologies arouse strong innovation resistance.

Second, self-efficacy and technical support can play roles to mitigate the detrimental effects caused by techno-stress and counter-productivity. It was found that techno-overload and techno-insecurity have interactions with self-efficacy, and techno-uncertainty has an interaction with technical support, which has an impact on the relief of CWB. In addition, we confirmed that technical support reduces innovation resistance interacting with technooverload, techno-complexity, and techno-insecurity.

This study focused on techno-stress in terms of individual dimensions, but future research needs to investigate positive factors and negative research on techno-stress with specific fields in the Fourth Industrial Revolution. It is necessary to expand the survey targets to those who perform non-IT jobs to test the techno-stress theory. Finally, future research needs to investigate various aspects of the organization related to productivity or performance to build an expanded understanding of the impact of techno-stress on organizations.

Author Contributions: D.G.K.: writing—original draft preparation. D.G.K. collected and analyzed data. C.W.L.: writing - review and editing. All authors have read and agreed to the published version of the manuscript.

Funding: This research received no external funding.

Data Availability Statement: Data were generated by a survey form developed by this study.

Conflicts of Interest: The authors declare no conflict of interest.

\section{References}

1. Jones, S.S.; Heaton, P.S.; Rudin, R.S.; Schneider, E.C. Unraveling the IT productivity paradox-Lessons for health care. N. Engl. J. Med. 2012, 366, 2243-2245. [CrossRef]

2. $\quad$ Edwards, J.R.; Caplan, R.D.; Harrison, R.V. Person-Environment Fit Theory: Conceptual Foundations, Empirical Evidence, and Directions for Future Research; Oxford University Press: Oxford, UK, 1998; pp. $28-67$.

3. Tarafdar, M.; Tu, Q.; Ragu-Nathan, B.S.; Ragu-Nathan, T.S. The impact of technostress on role stress and productivity. J. Manag. Inf. Syst. 2007, 24, 301-328. [CrossRef]

4. Tu, Q.; Wang, K.; Shu, Q. Computer-related technostress in China. Commun. ACM 2005, 48, 77-81. [CrossRef]

5. Soylu, A.; Campbell, S.S. Physical and emotional stresses of technology on employees in the workplace. J. Employ. Couns. 2012, 49, 130-139. [CrossRef]

6. Tarafdar, M.; Gupta, A.; Turel, O. The dark side of information technology use. Inf. Syst. J. 2013, 23, 269-275. [CrossRef]

7. Brod, C. Technostress: The Human Cost of the Computer Revolution; Addison Wesley Publishing Company: Boston, MA, USA, 1984.

8. Arnetz, B.B.; Wiholm, C. Technological stress: Psychophysiological symptoms in modern offices. J. Psychosom. Res. 1997, 43, 35-42. [CrossRef]

9. Weil, M.M.; Rosen, L.D. Technostress: Coping with Technology @WORK @HOME @ PLAY; John Wiley \& Sons: New York, NY, USA, 1997.

10. Hudiburg, R.A. Psychology of computer use: VII. Measuring technostress: Computer-related stress. Psychol. Rep. 1989, 64, 767-772. [CrossRef] 
11. Ayyagari, R.; Grover, V.; Purvis, R. Technostress: Technological antecedents and implications. MIS Q. 2011, 35, 831-858. [CrossRef]

12. Ragu-Nathan, T.S.; Tarafdar, M.; Ragu-Nathan, B.S.; Tu, Q. The consequences of technostress for end users in organizations: Conceptual development and empirical validation. Inf. Syst. Res. 2008, 19, 417-433. [CrossRef]

13. Schellhammer, S.; Haines, R.; Klein, S. Investigating technostress in situ: Understanding the day and the life of a knowledge worker using heart rate variability. In Proceedings of the 2013 46th Hawaii International Conference on System Sciences, Wailea, HI, USA, 7-10 January 2013; Volume 46, pp. 430-439. [CrossRef]

14. Salanova, M.; Llorens, S.; Cifre, E. The dark side of technologies: Technostress among users of information and communi-cation technologies. Int. J. Psychol. 2013, 48, 422-436. [CrossRef]

15. Fox, S.; Spector, P.E.; Miles, D. Counterproductive work behavior (CWB) in response to job stressors and organizational justice: Some mediator and moderator tests for autonomy and emotions. J. Vocat. Behav. 2001, 59, 291-309. [CrossRef]

16. Spector, P.E.; Fox, S. An emotion-centered model of voluntary work behavior: Some parallels between coun-terproductive work behavior (CWB) and organizational citizenship behavior (OCB). Hum. Resour. Manag. Rev. 2002, 12, 269-292. [CrossRef]

17. Chang, K.; Smithikrai, C. Counterproductive behaviour at work: An investigation into reduction strategies. Int. J. Hum. Resour. Manag. 2010, 21, 1272-1288. [CrossRef]

18. Gruys, M.L.; Sackett, P.R. Investigating the dimensionality of counterproductive work behavior. Int. J. Sel. Assess. 2003, 11, 30-42. [CrossRef]

19. Han, K.-H. Multi-dimensional approach of the determinants and moderators on production employees' counter-productive work behavior. Korean J. Bus. Adm. 2008, 21, 2771-2798.

20. Kang, M.-Y.; Han, N.-Y.; Bae, S.-W. A study on the effects of emotional labor on counterproductive work behavior via burnout. Manag. Inform. Syst. Rev. 2017, 36, 309-327.

21. Yoon, Y.-I.; Ha, D.-H. A moderating effect of leisure activities on the causal relationship between emotional dissonance and counterproductive work behavior in hotel employees. Int. J. Tour. Manag. Sci. 2016, 31, 393-412.

22. Oh, S.-K.; Yoon, H.-H. A study on the relationship between empathy, communicative responsiveness, burnout, and counterproductive work behavior of employees in the deluxe hotels. J. Foodserv. Manag. 2018, 21, 77-100.

23. Sheth, J. Psychology of Innovation Resistance: The Less Developed Concept in Diffusion Research; College of Commerce and Business Administration, University of Illinois at Urbana-Champaign: Champaign, IL, USA, 1981; pp. 273-282.

24. Ram, S. A Model of Innovation Resistance; Association for Consumer Research: Provo, UT, USA, 1987; Volume 14, pp. $208-212$.

25. Laukkanen, T.; Sinkkonen, S.; Kivijärvi, M.; Laukkanen, P. Innovation resistance among mature consumers. J. Consum. Mark. 2007, 24, 419-427. [CrossRef]

26. Kotter, J.P.; Price, D. Leading change: Why transformation efforts fail. Harv. Bus. Rev. 1995, 73, 59-67.

27. Oreg, S. Resistance to change: Developing an individual measure. J. Appl. Psychol. 2003, 88, 680-693. [CrossRef]

28. Ram, S. Successful innovation using strategies to reduce consumer resistance: An empirical test. J. Product. Innov. Manag. 1989, 14, 20-34. [CrossRef]

29. Brillhart, P.E. Technostress in the workplace: Managing stress in the electronic workplace. J. Am. Acad. Bus. 2004, 5, 302-307.

30. Derks, D.; Bakker, A.B. New ways of working: Impact on working conditions, work-family balance, and well-being. Hum. Perform. Manag. 2014, 230, 123-141.

31. Tammy, D.A.; David, E.L.; Herst, C.S.; Bruck, M.S. Consequences associated with work-to-family conflict: A review and agenda for future research. J. Occup. Health Psychol. 2010, 5, 278-308.

32. Cousins, K.D.; Robey, D. Human agency in a wireless world: Patterns of technology use in nomadic compu-ting environments. Inform. Organ. 2005, 15, 151-180. [CrossRef]

33. Belletier, C.; Charkhabi, M.; Pires de Andrade Silva, G.; Ametepe, K.; Lutz, M.; Izaute, M. Wearable cognitive assistants in a factory setting: A critical review of a promising way of enhancing cognitive perfor-mance and well-being. Cognit. Technol. Work 2019, 23, 103-116. [CrossRef]

34. Gilboa, S.; Shirom, A.; Fried, Y.; Cooper, C. A meta-analysis of work demand stressors and job performance: Examining main and moderating effects. Pers. Psychol. 2008, 61, 227-271. [CrossRef]

35. Mahboob, A.; Khan, T. Technostress and its management techniques: A literature review. J. Hum. Resour. Manag. 2008, 4, 28-31. [CrossRef]

36. Tarafdar, M.; Tu, Q.; Ragu-Nathan, T.S.; Ragu-Nathan, B.S. Crossing to the dark side: Examining creators, outcomes, and inhibitors of technostress. Commun. ACM 2011, 54, 113-120. [CrossRef]

37. Wang, K.; Shu, Q.; Tu, Q. Technostress under different organizational environments: An empirical investiga-tion. Comput. Hum. Behav. 2008, 24, 3002-3013. [CrossRef]

38. Gene, M.A. A meta-analysis of burnout with job demands, resources, and attitudes. J. Vocat. Behav. 2011, 79, 549-562.

39. Baron, R.M.; Kenny, D.A. The moderator-Mediator variable distinction in social psychological research: Conceptual, strategic, and statistical considerations. J. Pers. Soc. Psychol. 1986, 51, 1173-1182. [CrossRef] [PubMed]

40. Bandura, A. Perceived self-efficacy in cognitive development and functioning. Educ. Psychol. 1993, 28, 117-148. [CrossRef]

41. Wood, R.E.; Bandura, A. Impact of conceptions of ability on self-regulatory mechanism and complex decision making. J. Person. Soc. Psychol. 1989, 56, 407-415. [CrossRef]

42. Kanfer, R. Motivation and individual differences in learning: An integration of developmental, differential and cognitive perspectives. Learn. Individ. Differ. 1990, 2, 221-239. [CrossRef] 
43. Gist, M.E. Self-efficacy: Implications for organizational behavior and human resource management. Acad. Manag. Rev. 1987, 12, 472-485. [CrossRef]

44. Hackman, J.R.; Oldham, G.R. Development of the job diagnostic survey. J. Appl. Psychol. 1975, 60, 159-170. [CrossRef]

45. Eden, D.; Zuk, Y. Sea sickness as a self-fulfilling prophecy: Raising self-efficacy to boost performance at sea. J. Appl. Psychol. 1995, 80, 628-635. [CrossRef] [PubMed]

46. Riggs, M.L.; Knight, P.A. The impact of perceived group success-failure on motivational beliefs and attitudes: A casual model. J. Appl. Psychol. 1994, 79, 755-766. [CrossRef]

47. Kwon, O.-Y.; Pyum, H.-S. The structural relationships between perceived organizational support, ethical leadership, trust in leader, and job satisfaction: Salesperson's perspective. Korean Manag. Consult. Rev. 2018, 18, 49-59.

48. Meier, K.J.; Hicklin, A. Employee turnover and organizational performance: Testing a hypothesis from clas-sical public administration. J. Public Adm. Res. Theor. 2008, 18, 573-590. [CrossRef]

49. Korunka, C.; Hoonakker, P.; Carayon, P. Quality of working life and turnover intention in information tech-nology work. Hum. Factors Ergon. Manuf. 2008, 18, 409-423. [CrossRef]

50. Charkhabi, M. Do cognitive appraisals moderate the link between qualitative job insecurity and psychologi-cal-behavioral well-being? Int. J. Workplace Health Manag. 2018, 11, 424-441. [CrossRef]

51. Kim, D.-G.; Kang, S.-M. The impact of technostress on counter-productivity. Manag. Inform. Syst. Rev. 2020, 39, 1-15.

52. Kim, G.-A.; Kim, S.-H. The Relationship between technostress and continuance commitment within organi-zations: The moderating effects of involvement facilitation and technical support provision. J. Soc. eBus. Stud. 2015, 20, 153-166.

53. Ahmad, U.N.U.; Amin, S.M.; Ismail, W.K.W. Moderating effect of technostress inhibitors on the relationship between technostress creators and organizational commitment. J. Teknol. 2014, 67, 51-62. 